\title{
Lithium and nuclear fusion
}

\section{Can lithium reserves sustain a programme for the generation of power by controlled thermonuclear fusion? Nick Walton and Ed Spooner offer this assessment}

The authors are based at the Department of Geology and Mineralogy, University of Oxford.

THE postponements by the EEC of 1 a decision on the siting of the Joint European Torus (JET) nuclear fusion project, worrying setbacks though these are for European fusion research, should not be allowed to detract from other considerations regarding fusion power and, specifically, questions about ore reserves of lithium and future lithium demand.

Of the three possible practical methods for obtaining power from fusion, the one based on the deuteriumtritium reaction is the most favourable since the "ignition" temperature is the lowest (about $10 \mathrm{keV}$ ) and the average energy gain is the highest (about 1,800 per fusion reaction). The first generation of nuclear fusion reactors will therefore need a continuous supply of both deuterium and tritium fuel.

Deuterium constitutes 0.015 atom \% of naturally occurring hydrogen, and is relatively inexpensive to produce from sea water. Since sea water contains about $33 \mathrm{~g} \mathrm{~m}^{-3}$ deuterium, the world's resources of deuterium are large (about $5 \times 10^{13}$ tonnes) and readily available. Tritium, however, is an unstable isotope with a short halflife of 12.3 years, and occurs naturally only in trivial amounts as a product of cosmic ray bombardment in the upper atmosphere. A continuous supply of tritium for use in fusion reactors will, therefore, have to be produced artificially. The only practical method of doing this is to irradiate lithium with neutrons:

$$
\begin{aligned}
& { }^{6} \mathrm{Li}+\mathrm{n} \rightarrow{ }^{3} \mathrm{H}(\mathrm{T})+{ }^{4} \mathrm{He}+4.8 \mathrm{MeV} \\
& { }^{7} \mathrm{Li}+\mathrm{n} \rightarrow{ }^{3} \mathrm{H}(\mathrm{T})+{ }^{4} \mathrm{He}+\mathrm{n}^{\prime}-2.5 \mathrm{MeV}
\end{aligned}
$$

In a fusion reactor liquid lithium may be arranged as a circulating blanket surrounding the reacting plasma. Neutrons released by the fusion reactions can then be used to breed tritium fuel continuously, actually within this blanket.

The most useful of the two reactions is that involving ${ }^{6} \mathrm{Li}$, since this is exothermic and can add $4.8 \mathrm{MeV}$ per nuclear reaction to the energy output of the deuterium-tritium fusion process itself. The capture cross-section of this reaction, however, peaks for slow neutrons at $0.3 \mathrm{MeV}$; it would thus use only a small proportion of the total neutrons available, since the spectrum of the neutron flux peaks at $14.1 \mathrm{MeV}$. The ${ }^{7} \mathrm{Li}$ reaction is therefore impor- tant, even though it is endothermic, because in addition to producing tritium it acts as a moderator of fast neutrons since its capture cross-section peaks at about $8 \mathrm{MeV}$. This reaction slows fast neutrons down sufficiently for them to interact exothermically with ${ }^{6} \mathrm{Li}$ and produce more tritium.

A blend of ${ }^{6} \mathrm{Li}$ and ${ }^{7} \mathrm{Li}$ can therefore balance the opposing requirements of tritium breeding and production of additional energy. The isotopic composition of natural lithium $\left(7.4 \%{ }^{\circ} \mathrm{Li}\right.$; $92.6 \%{ }^{7} \mathrm{Li}$ ) corresponds closely to an optimum mixture; it is worth noting, however, that the tritium required by the first nuclear fusion reactors will have to be produced by irradiating concentrated ${ }^{\circ} \mathrm{Li}$ with the slow neutrons available from fission reactors. Additionally, liquid lithium is theoretically superior to liquid sodium as a coolant. It combines such favourable properties as a low density, a high boiling point, a high heat capacity and a high heat transfer coefficient. Hence, an equally important factor which is likely to ensure that lithium will be used in nuclear fusion reactors is that it is theoretically highly suitable for use as the coolant which transfers heat from reactor cores.

Natural lithium in the form of a liquid metal blanket will, therefore, probably be essential in nuclear fusion reactors since it alone can effectively combine the three diverse requirements of tritium breeding. neutron moderation and heat transfer. Total cumulative Western world lithium demand up to the year 2030 may conveniently be considered as the sum of four requirements, each of which can be evaluated separately (see Table 1): non-fusion use up to the year 2000; non-fusion use from 2000 to 2030; capital requirements of lithium to be used in multi-purpose blankets for fusion reactors; and lithium consumption by nuclear reactions in the liquid metal blankets of fusion reactors.

\section{Non-fusion demand}

Western world consumption of lithium in 1974 was about 3,900 tonnes metal. Demand for lithium, which is used principally as an additive to aluminium potlines, in the manufacture of glass, ceramics, greases and specialised lithium chemicals, and in welding and brazing fluxes, increased at about $5 \%$ per year in the 1960s and early 1970s. However, the unique properties of lithium are only now being exploited for highly specialised, non-substitutable applications in a variety of new and expanding industries. This has resulted in a sharp rise to a $15 \%$ annual growth rate in the last few years, a rate which is likely to continue for the immediate future at least. Over the past 65 years annual growth in demand in the United States has fluctuated considerably in response to changing economic circumstances, but has averaged about $10 \%$.

Two maior new applications of lithium can be foreseen which are likely to sustain a high rate of growth in demand. These are in high power/ weight ratio batteries, and as the liauid metal coolant in fast breeder nuclear fission reactors. Annual growth in demand for lithium over the next 25 years is thus likely to be between $5 \%$

Table 1 Estimates of Western world non-fusion and fusion demand for lithium up to the year 2030

(a) Western world lithium consumption in 19741:

(b) Non-fusion demand up to the year 2000:

3,900 tonnes metal

\begin{tabular}{lrrr} 
Growth rate in demand & $5 \%$ & $10 \%$ & $15 \%$ \\
\hline $\begin{array}{lrrr}\text { Annual demand in } \\
2000 \text { (tonnes) }\end{array}$ & 13,900 & 46,500 & 147,600 \\
$\begin{array}{l}\text { Cumulative demand } \\
\text { by 2000 (tonnes) }\end{array}$ & 200,000 & 426,000 & 958,000
\end{tabular}

(c) Non-fusion demand from 2000 to 2030 , and cumulative non-fusion demand up to the year 2030:

\begin{tabular}{lccr}
$\begin{array}{c}\text { Demand growth rate } \\
\text { up to 2000 }\end{array}$ & $5 \%$ & $10 \%$ & $15 \%$ \\
$\begin{array}{c}\text { Demand growth rate } \\
\text { from 2000 to 2030 }\end{array}$ & $5 \%$ & $10 \%$ & $5 \%$ \\
\hline $\begin{array}{c}\text { Annual demand in } \\
2030 \text { (tonnes) }\end{array}$ & 60,000 & 811,000 & 638,000 \\
$\begin{array}{c}\text { Cumulative demand } \\
\text { between 2000 and } \\
2030 \text { (tonnes) }\end{array}$ & 923,000 & 7.6 million & 9.8 million \\
$\begin{array}{c}\text { Total cumulative demand } \\
\text { up to 2030 (tonnes) }\end{array}$ & 1.1 million & 8.1 million & 10.8 million
\end{tabular}

(d) Capital requirements of lithium needed in fusion reactors from 2000 to 2030 :

(e) Lithium consumption by nuclear reactions in liquid metal blankets from 2000 to 2030 :

(f) Total Western world cumulative demand for lithium by the year 2030 :

$\sim 1.5$ million tonnes $\sim 80,000$ tonnes

${ }^{1}$ Luckenbach, W. F., Mining Annual Review 1975, 112 (Mining Journal, London; 1975). 
and $15 \%$. Continual development of new applications is likely to sustain a higher rather than a lower rate, and this will lead to a cumulative demand for lithium by the year 2000 of between 200,000 and 958,000 tonnes metal (Table 1). The rate of increase in demand for the years 2000 to 2030 is also likely to be between $5 \%$ and $15 \%$. The figures suggest that cumulative Western world non-fusion demand for lithium should be between 1.1 and 10.8 million tonnes. Because of the discovery of quantitatively important new applications for lithium, it is considered that estimates in the upper part of the range are more reasonable.

\section{Fusion demand}

Future requirements of lithium for nuclear fusion reactors can be divided into two types: an initial inventory of lithium which will be used in the cooling blankets - this is estimated (Ribe, F. L., Reviews of Modern Physics, 47, $7-41$; 1975) to need between 600 and 1,700 tonnes per $3 \mathrm{GW}$ reactor; and a supply of lithium which will be used to replace the lithium destroyed by the nuclear reactions in the liquid metal cooling blankets (it is considered that this will be a relatively small quantity of about 13.5 tonnes per year per $3 \mathrm{GW}$ reactor).

In order to estimate the quantity of lithium which will be needed if a nuclear fusion programme does develop, a model calculation is used which is based on a set of postulates. These are:

- Commercial nuclear fusion reactors will start to be built in about 25 years time. For technical reasons the power generative capacity of these machines is likely to be in the $2-5 \mathrm{GW}$ range, and, therefore, larger than the current largest power stations which produce only about $1 \mathrm{GW}$.

- The rate of installation of nuclear fusion reactors between 2000 and 2030 will be comparable to the planned rate of installation of fission reactors in the United States between 1970 and 2000. A lower and more likely figure for the planned amount of generating capacity to be installed by 2000 of $750 \mathrm{GW}$ is taken, rather than the more normally quoted figure of $1,000 \mathrm{GW}$.

- The Western European countries, and possibly other nations, will also implement a nuclear fusion programme which will together be approximately the same size as that in the United States.

Hence, assuming a mean fission reactor size of about $1 \mathrm{GW}$ and a comparable building rate for fission and fusion reactors, approximately 750 fusion reactors might be installed in the United States between 2000 and 2030. At about 1,000 tonnes of lithium per fusion reactor, this would lead to a cumulative demand for lithium of 750,000 tonnes by the year 2030 . If usage in the rest of the Western world is comparable, then cumulative Western world demand by 2030 would be about 1.5 million tonnes. This figure is comparable to the minimum estimate for cumulative non-fusion demand (1.1 million tonnes, Table 1). Cumulative demand for lithium to replenish liquid metal cooling blankets would be about 80,000 tonnes.

The total cumulative Western world demand for lithium up to the year 2030 could therefore lie between 3 and 12 million tonnes, depending principally on the growth rate of non-fusion uses.

\section{Lithium occurrence and reserves}

The concentration of lithium in the Earth's crust is of the order of $20 \mathrm{ppm}$, and in sea water about $0.2 \mathrm{ppm}$. Because of the small size of its univalent cation (ionic radius of $\mathrm{Li}^{+}=0.68 \AA$ ), lithium is an incompatible element which concentrates in the late-stage silicate melt and aqueous fluid phases formed during solidification of magmas. Crystallisation from these residual liquids has produced the unusually coarse grained acid igneous rocks called pegmatites. However, less than $10 \%$ of all known pegmatites contain suites of rare minerals, and only some of these are rich in lithium.

Table 2 Western world identified resoures of lithium

\begin{tabular}{|c|c|c|c|c|c|}
\hline & & & & Identified & esources ${ }^{2}$ \\
\hline Country & Location & Type of deposit & $\begin{array}{l}\text { Total } \\
\text { identified } \\
\text { resources } \\
\text { (tonnes Li) }^{1}\end{array}$ & $\begin{array}{l}\text { Proven and } \\
\text { probable } \\
\text { reserves } \\
\text { (tonnes Li) }\end{array}$ & $\begin{array}{l}\text { Possible } \\
\text { additional } \\
\text { reserves } \\
\text { (tonnes Li) }\end{array}$ \\
\hline USA & $\begin{array}{l}\text { Kings Mountain, } \\
\text { N. Carolina }\end{array}$ & Large pegmatites & 313,000 & 441,000 & $560,000^{3}$ \\
\hline USA & Black Hills, & Smoll neometito & not & & \\
\hline USA & Other areas & $\begin{array}{l}\text { Small pegmatites } \\
\text { Small pegmatites }\end{array}$ & $\begin{array}{l}\text { specified } \\
\text { not }\end{array}$ & & 10,000 \\
\hline USA & Silver Peak, Nevada & Underground brine & specified & & 1,000 \\
\hline USA & & $(300 \mathrm{ppm} \mathrm{Li})$ & 553,000 & 454,000 & $2,000,000$ \\
\hline & California & (70 ppm Li) & 40,000 & 10,000 & 30,000 \\
\hline USA & $\begin{array}{l}\text { Great Salt Lake, } \\
\text { Utah }\end{array}$ & $\begin{array}{l}\text { Surface brine } \\
(60 \mathrm{ppm} \mathrm{Li})\end{array}$ & 707,000 & $\begin{array}{l}\text { not } \\
\text { specified }\end{array}$ & $\begin{array}{l}\text { not } \\
\text { specified }\end{array}$ \\
\hline USA & $\begin{array}{l}\text { Salton Sea, } \\
\text { California }\end{array}$ & $\begin{array}{l}\text { Underground geothermal } \\
\text { brine }(210 \mathrm{ppm} \mathrm{Li})\end{array}$ & 1.000 .000 & & $1,000,000$ \\
\hline USA total (ro & & & $2,600,000$ & 900,000 & $3,000,000$ \\
\hline $\begin{array}{l}\text { Canada } \\
\text { Canada } \\
\text { Canada } \\
\text { Canada total }\end{array}$ & $\begin{array}{l}\text { Barante, Quebec } \\
\text { Bernic Lake, Manitoba } \\
\text { Other areas } \\
\text { led) }\end{array}$ & $\begin{array}{l}\text { Medium pegmatites } \\
\text { Medium pegmatites } \\
\text { Pegmatites }\end{array}$ & $\begin{array}{r}86,000 \\
73,000 \\
317,000 \\
\mathbf{4 7 6 , 0 0 0}\end{array}$ & $\begin{array}{l}76,000 \\
41,000\end{array}$ & $\begin{array}{l}180,000 \\
\mathbf{1 8 0 , 0 0 0}\end{array}$ \\
\hline $\begin{array}{l}\text { S.W. Africa } \\
\text { Rhodesia }\end{array}$ & $\begin{array}{l}\text { Walvis Bay } \\
\text { Bikita tinfield }\end{array}$ & $\begin{array}{l}\text { Small pegmatites } \\
\text { Medium pegmatites }\end{array}$ & $\begin{array}{l}17,800 \\
83,900\end{array}$ & $\begin{array}{r}4,000 \\
82,000\end{array}$ & \\
\hline Zaire & Manono and Kittdo & Large pegmatites & $\begin{array}{l}1,000,000 \\
\text { (inferred) }\end{array}$ & & $1,000,000^{3}$ \\
\hline Africa total ( $\mathrm{r}$ & & & $\mathbf{1 , 1 0 0 , 0 0 0}$ & 86,000 & $1,000,000$ \\
\hline W. Australia & Coolgardie & Small pegmatites & 15,000 & not & not \\
\hline S. America & Salar de Atacama & Underground brine & $1,300,000$ & & $1,000,000^{3}$ \\
\hline Western world total (rounded) & & & $5,000,000$ & $1,100,000$ & $5,800,000$ \\
\hline & & & & 7,00 & 000 \\
\hline
\end{tabular}

1 Norton, J. J., USGS Professional Paper, 820, 365-378; 1972.

2 Kunosz, I. A., in Industrial Minerals and Rocks (AIME, 1974).

3 These figures are hypothetical resources that are geographically predictable as existing in known districts. 
The clinopyroxene mineral spodumene $\left(\mathrm{LiA}_{1} \mathrm{Si}_{2} \mathrm{O}_{6}\right)$ is the most important lithium mineral. It occurs particularly in a small number of large unzoned pegmatites in North America. Lepidolite mica $\left(\mathrm{KLi}_{2} \mathrm{Al}\left(\mathrm{Si}_{4} \mathrm{O}_{10}\right)(\mathrm{F}, \mathrm{OH})_{2}\right)$, eucryptite $\left(\mathrm{LiAlSiO}_{4}\right)$, petalite $\left(\mathrm{LiAlSi}_{4} \mathrm{O}_{10}\right)$ and the phosphate amblygonite $\left(\mathrm{LiAl}\left(\mathrm{PO}_{4}\right)(\mathrm{F}, \mathrm{OH})\right)$ are the only other lithium minerals of economic importance. These minerals tend to occur as replacements in the central zones of smaller, zoned pegmatites which occur in Southern Africa and elsewhere.

Lithium also occurs concentrated in certain surface and underground brines. For example, the underground brines at Silver Peak, Nevada contain about 300 ppm Li, the Great Salt Lake, Utah contains about $60 \mathrm{ppm} \mathrm{Li}$ and the Salton Sea geothermal underground brine in California contains about $210 \mathrm{ppm} \mathrm{Li}$. The Silver Peak brine is the largest known single reserve of lithium in the world and contains identified possible reserves of 2 million tonnes lithium metal. Lithium supply has recently become dominated by production from brines, and is likely to remain so in the future.

Unlike sodium and potassium, lithium does not occur in economically significant concentrations in marine evaporites because the concentration of lithium in sea water is low (about $0.2 \mathrm{ppm}$ ) and the solubilities of its salts are high.

For comparison with the estimates of cumulative Western world demand for lithium by the year 2030 given in Table 1, information on resources of lithium in economically workable concentrations (ore and brine deposits) is summarised in Table 2. This suggests that Western world reserves of lithium which are identified at the present time are about 5-7 million tonnes of metal. The amount of lithium in undiscovered deposits would add a considerable, but unknown, amount to this figure. In the past there has not been a large demand for lithium and, as a result, exploration for new deposits has not been particularly rigorous or extensive. The likelihood of discovering new large lithium ore deposits, therefore, is reasonably strong.

The figure of 5-7 million tonnes for identified Western world lithium reserves is comparable to the estimate of 3-12 million tonnes for Western world cumulative lithium demand up to the year 2030. Providing that exploration for new lithium-enriched brines and ore deposits is as successful as would seem probable, it can be concluded that the Western world's resources of lithium are capable of sustaining a programme for the generation of power by controlled thermonuclear fusion. However, the fact that the figures for cumulative demand and presently known sources are similar suggests that there is no cause for the complacency shown in recent assessments (see, for example, Hubbert, $M$. K., Scientific American, 225, 61-70; 1971, and Proceedings of the Fourth
International Conference on the peaceful uses of atomic energy (Geneva) 7, 467 (UN and IAEA, Geneva; 1972)). This is particularly the case for the European countries which possess no presently identified significant lithium resources. This fact suggests a necessity for exploration in Europe if dependence on imports is to be minimised.

Four other conclusions may be drawn: - Non-fusion demand for lithium is likely to be greater than or equal to fusion demand.

- Demand for lithium is certain to rise, and, therefore, lithium production will have to increase quite considerably. If, for example, the total growth rate in demand were maintained as high as $10 \%$ over the next fifty-five years, as over the past fifty-five years, production capacity would have to increase by a factor of about 200 .

- A large amount of liquid lithium metal must be tied up in the blanket of each new fusion plant. This represents a sudden, large increased demand equal to one-quarter of current annual consumption. This capital demand for lithium has invariably been overlooked when assessing the availability of lithium supplies for nuclear fusion.

- The future demand for lithium will be relatively inelastic since the important new uses being developed are all based upon specific and unique properties of the metal. There are, therefore, no known lithium substitutes which could significantly depress projected growth figures.

\section{UK ENERGY}

\section{A question of balance}

The widely heralded public debate on the national energy strategy opens next Tuesday, one week after publication of the Department of Energy's report singling out the coal and nuclear industries as crucial factors in the country's energy future. Allan Piper reports

ON the premise that the best way of planning a forward march is to stand well back and view the terrain ahead, Britain's Energy Secretary, Mr Anthony Wedgwood Benn, has started mapping out the nation's energy strategy with his feet in the right place. Consider the position. The country is caught in industrial recession, and inflation is at an uncomfortable level. The demand for energy has slumped. The coal industry, committed to an ambitious expansion plan after years in decline, is producing more fuel than the country can burn, and is staggering beneath the expensive burden of record stockpiles.
The nuclear programme, years behind target and way over budget, is beset by niggling technological teething troubles, and faces powerful environmentalist opposition. Additional competitive pressures stem from the rosy opportunity for national energy sufficiency offered by North Sea oil and gas. But both must be carried through to the 1990 s, when North Sea reserves will be running down and high world prices make energy imports undesirable.

It all means that when $\mathrm{Mr}$ Benn moves onwards from next Tuesday he will be juggling as he goes. Clutching the medium-term North Sea opportunities firmly in one hand, and manipulating nuclear options with the other, he must all the while keep the coal industry safely off the ground. Neither can he afford to drop any of the five realistic alternative possibilities-solar, wave, wind, tidal and geothermal power. Fusion is regarded as too distant. Thus, by the time the energy gap looms, the whole act must be sufficiently well coordinated to allow just one firm step across.

Events of the past fortnight have shown that the Energy Secretary will be jostled from every side. In the build up to the coming energy forum, organisations as diverse as the coal industry, the UK Atomic Energy Authority (UKAEA) and the Confederation of British Industry (CBI) on the one hand, and Friends of the Earth (FOE), consumer groups, and trades unions on the other, have deluged his department with a welter of initial positioning statements. They indicate clearly that few of the 120 participants involved will fail to adopt attitudes largely of self interest.

\section{ACORD report}

The simultaneous publication of a long-awaited Department of Energy (DEN) report on energy research and development (R\&D) strategy may help, however, to keep the energy secretary on a firm footing. Its recommendations, while arguably as predictable as those of the various positioning papers, are at least based on wider considerations. Put together by a working group of the Advisory Council on Research and 